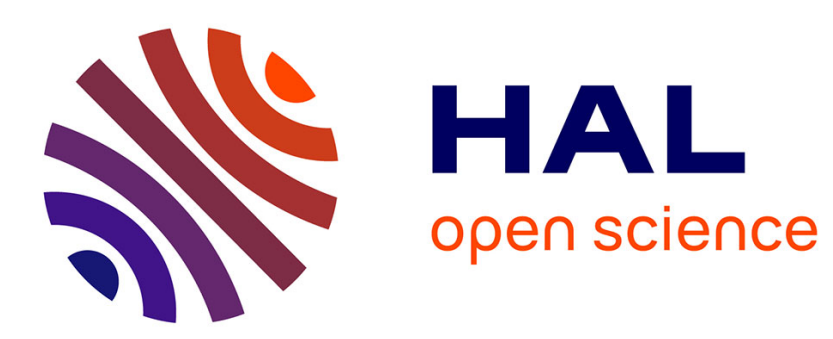

\title{
Numerical Study of Spall in an Aluminum Alloy under Planar Impact Loading
}

S. Hanim, J. Klepaczko

\section{To cite this version:}

S. Hanim, J. Klepaczko. Numerical Study of Spall in an Aluminum Alloy under Planar Impact Loading. Journal de Physique IV Proceedings, 1997, 07 (C3), pp.C3-791-C3-796. 10.1051/jp4:19973134 . jpa-00255421

\section{HAL Id: jpa-00255421 https://hal.science/jpa-00255421}

Submitted on 1 Jan 1997

HAL is a multi-disciplinary open access archive for the deposit and dissemination of scientific research documents, whether they are published or not. The documents may come from teaching and research institutions in France or abroad, or from public or private research centers.
L'archive ouverte pluridisciplinaire HAL, est destinée au dépôt et à la diffusion de documents scientifiques de niveau recherche, publiés ou non, émanant des établissements d'enseignement et de recherche français ou étrangers, des laboratoires publics ou privés. 


\title{
Numerical Study of Spall in an Aluminum Alloy under Planar Impact Loading
}

\author{
S. Hanim and J.R. Klepaczko
}

Laboratoire de Physique et Mécanique des Matériaux, Institut Supérieur de Génie Mécanique et Productique, Université de Metz, Ile du Saulcy, 57045 Metz cedex 01, France

\begin{abstract}
Résumé. Les effets de la température et de la vitesse sur le comportement des matériaux sont liés aux processus micromécaniques activés thermiquement, notamment lors de la création de surfaces libres de rupture. Pour prédire l'endommagement par écaillage des matériaux sous chargement dynamique, nous avons déterminé dans une première étude numérique, dans le cas élastique, la contrainte critique minimale d'écaillage en fonction du temps de chargement critique correspondant. Comme la rupture dynamique est influencée par les propriétes physiques du matériau, de ce fait un critère cumulatif [1] lié à l'énergie d'activation de séparation du matériau et la loi constitutive viscoplatique tenant compte des effets de la déformation, de la vitesse de déformation et de la température, ont été implementé dans un code de calcul par éléments finis. Les profils de vitesse de la surface libre calculés pour plusieur vitesses d'impact, montrent la création de nouvelles surfaces libres dans la plaque cible. L'influence des parametres physique est discuté sur la base des résultats numérique.
\end{abstract}

\begin{abstract}
Numerical analysis has been performed by implementation of a cumulative dynamic fracture criterion [1] which depends on the free energy of activation of separation, temperature and the load history. First series of calculation has been performed for elastic case to obtain minimum critical spall-fracture stress as a function of critical time of loading. Next, a viscoplastic constitutive relation which includes the effects of strain hardening, strain rate and temperature, along with cumulative criterion and heat conduction, because of temperature increase due to volume dilatation and dissipation of plastic work, has been implemented in FE code. Also, free surface velocity-time profiles have been calculated for a number of impact velocities, showing creation of new free surfaces inside the target plate. The influence of physical parameters is discussed on the basis of numerical results.
\end{abstract}

\section{INTRODUCTION}

Spallation is a particular kind of dynamic fracture and fragmentation. The first observation of spall has been probably reported in XIX century. The spall mechanics became the subject of interest in many laboratories for its extent to a variety of applications, particularly in terminal ballistics and detonics. A comprehensive discussion of the physical features associated with dynamic fracture of solids can be found for example in the review articles by Meyers and Aimone [2], and Curran, Seaman and Shockey [3].

In order to make a more detailed study of spalling, it is necessary to use plane stress wave generators or plate/plate impact configuration. This group of methods represents the most common procedure for investigating the plane waves in materials. This is due to the relative ease with which the properties of waves can be studied. It is clear that in such experiment the elastic or plastic wave propagation, strain rate and temperature effects, are all superimposed at the same time. It is attempted in this paper to discuss by numerical analysis the influence of these factors on spallation of an aluminum alloy. A series of numerical simulations was performed to model spall behavior of aluminum alloy 7020 -T6, by implementing in a FE code, elasto-viscoplastic constitutive relations, thermal coupling and the cumulative fracture criterion which includes effects of temperature and the history of loading [1].

\section{REMARKS ON EXPERIMENTAL TECHNIQUE}

Plate impact experiment was used to produce plane waves in order to study the phenomenon of spallation in 7020-T6 alloy. This experimental technique seems to be the best because the velocity and planarity of impact can be precisely controlled. The material studied was an aluminum alloy 7020-T6, with density $\rho=2.780 \mathrm{~g} / \mathrm{cm}^{3}$, Young's modulus $E=72.0 \mathrm{GPa}$ and Poisson's ratio $v=0.33$. Different target lengths and one target diameter were used in experiments: $2 \mathrm{~mm} \leq \mathrm{h} \leq 10 \mathrm{~mm}$ and $\mathrm{d}=57 \mathrm{~mm}$. The longitudinal elasticwave speed under uniaxial strain condition was found as $C_{1}=6.0878 \mathrm{~mm} / \mu \mathrm{s}$.

Preliminary compression tests, [4], have been performed on this aluminum alloy. It was found that this alloy after rolling and treatment $\mathrm{T} 6$ is moderately rate sensitive with relatively high strain hardening rate. 
Symmetric impact experiments using a gas-gun [5], were performed in vacuum to find critical conditions of spall which occurs in the interior of the target plate made of 7020-T6. The gas-gun was completely automatized and was equiped with an optical system to measure the impact velocity of the projectile. The specimens were soft recovered with a specially designed catcher to prevent any secondary damage. The thickness of impactor was half of the target thickness, this geometry was used in order to assure the proper interaction of the waves in the interior of the target.

\section{CONSTITUTIVES EQUATIONS}

The aluminum alloy is assumed to obey rate dependent J2 (Huber-Mises) flow theory of plasticity with isotropic hardening. It is furthermore assumed that the total deformation rate can be decomposed additively into elastic and inelastic part.

$$
\dot{\varepsilon}_{i j}=\dot{\varepsilon}_{i j}^{e}+\dot{\varepsilon}_{i j}^{p}
$$

The elastic deformation rate is governed by Hooke's law, eq.(2), and the inelastic one is governed by the rate equations (2)-(6).

Governing equations:

Elasticity:

Plasticity:

$$
\dot{\sigma}_{i j}=2 \mu \dot{\varepsilon}_{i j}^{e l}+\lambda \delta_{i j} \dot{\varepsilon}_{k k}^{e l}
$$

- yield function: $\sqrt{\frac{3}{2} s_{i j} s_{i j}}-\sigma_{y}\left(\bar{\varepsilon}^{p l}\right)=0 \quad s_{i j}=\sigma_{i j}-\frac{1}{3} \delta_{i j} \sigma_{k k}$

- equivalent plastic strain: $\bar{\varepsilon}^{p l}=\int_{0}^{t} \dot{\bar{\varepsilon}}^{p l} d t \quad \quad \dot{\bar{\varepsilon}}^{p l}=\sqrt{\frac{2}{3} \dot{\varepsilon}_{i j}^{p l} \dot{\varepsilon}_{i j}^{p l}}$

- plastic flow rule:

$$
\dot{\varepsilon}_{i j}^{p l}=\frac{3}{2} \frac{s_{i j}}{\sigma_{e}} \dot{\bar{\varepsilon}}^{p l}
$$

Here $\dot{\varepsilon}_{i j}^{p l}$ is the effective plastic strain rate, $\dot{\bar{\varepsilon}}^{\mathrm{pl}}$ is the equivalent plastic strain rate, $\sigma_{e}$ is the effective stress and $s_{i j}$ is the deviatoric part of the stress tensor.

The strain rate dependence of material is given by a power constitutive relation [6] of the form :

$$
\begin{gathered}
\bar{\sigma}=B(T)\left(\bar{\varepsilon}^{p l}+\varepsilon_{0}\right)^{n(T)}\left(1+\left(\frac{\dot{\bar{\varepsilon}}^{p l}}{\dot{\varepsilon}_{0}}\right)^{m(T)}\right) \\
\text { with } \quad B(T)=B_{0}\left(1-q \frac{T}{T_{m}}\right) \quad n(T)=n_{0}\left(1-\frac{T}{T_{m}}\right) \quad m(T)=m_{0} \frac{T}{T_{m}}
\end{gathered}
$$

where $\bar{\sigma}$ is the equivalent yield stress at non-zero plastic strain rate, $\mathbf{B}_{0}$ is the plasticity modulus and $\varepsilon_{0}$, $\dot{\varepsilon}_{0}$ are respectively the reference strain and the reference strain rate, $\mathrm{n}_{0}$ and $\mathrm{m}_{0}$ are the strain hardening exponent and the strain rate sensitivity, both at $\mathrm{T}=0 \mathrm{~K}, \mathrm{q}$ is the temperature sensitivity. Of course, before numerical analysis all of these material constants must be found. The material constants which describe strain hardening and strain rate and temperature sensitivity of aluminum alloy Al 7020-T6 are presented in the Table.1, [4].

Table 1.

\begin{tabular}{|c|c|c|c|c|c|c|c|}
\hline Const. & $\mathrm{B}_{0}$ & $\mathrm{q}$ & $\mathrm{T}_{\mathrm{m}}$ & $\mathrm{n}_{0}$ & $\mathrm{~m}_{0}$ & $\dot{\varepsilon}_{0}$ & $\varepsilon_{0}$ \\
\hline Value & 1352. & 1.118 & 877. & 0.289 & 0.2248 & $1.88 \mathrm{e}^{+12}$ & 0.007 \\
\hline Units & $\mathrm{MPa}$ & 1 & $\mathrm{~K}$ & 1 & 1 & $\mathrm{~s}^{-1}$ & 1 \\
\hline
\end{tabular}

\section{THERMOMECANICAL COUPLING}

Fast plastic deformation involves increases in temperature due to adiabatic heating. To accurately predict the response of material, the effect of temperature on the flow stress must be included in a constitutive model. Thus, in coupled themomechanical problems an additional field equation is added to the usual field equations. This additional equation, the heat conduction equation, provides a link between mechanical deformation fields and the additional unknown temperature field, $\mathrm{T}(\mathrm{x}, \mathrm{t})$, and is given by 


$$
\kappa \nabla^{2} \mathrm{~T}-\mathrm{T}=-\frac{\beta \sigma \dot{\varepsilon}^{\mathrm{pl}}}{\rho \mathrm{C}_{\mathrm{p}}}+\frac{\alpha}{\rho \mathrm{C}_{\mathrm{p}}} \frac{\mathrm{E}}{(1-2 v)} \mathrm{T}_{0} \operatorname{tr}\left(\dot{\varepsilon}^{\mathrm{el}}\right)
$$

where $\kappa$ is the thermal diffusivity, $\rho$ is the density, $C_{p}$ is the heat capacity, $\beta$ is Taylor-Quiney coefficient, $\alpha$ is the coefficient of thermal expansion, $E$ is Young's modulus, $v$ is Poisson's ratio, and $T_{0}$ is the initial temperature. The first term on the right represents heating due to irreversible plastic deformation and the second term represents changes of temperature due to the reversible thermoelastic effect. When the heat equation is introduced into FE code it can be shown then that the approximation of adiabatic heating transforms the problem to an ordinary differential equation which makes it possible to update the temperature in the constitutive subroutine. This ordinary differential equation can be integrated locally by the same subroutine as for the constitutive equations. Such approach makes the formulation computationally advantageous, then the equation of heat conduction takes the form :

$$
\dot{\mathrm{T}}=\frac{\beta \sigma \cdot \dot{\varepsilon}^{\mathrm{p}}}{\rho \mathrm{C}_{\mathrm{p}}}-\frac{\alpha}{\rho \mathrm{C}_{\mathrm{p}}} \frac{\mathrm{E}}{(1-2 v)} \mathrm{T}_{0} \operatorname{tr}\left(\dot{\varepsilon}^{\mathrm{e}}\right)
$$

Equation (8) has been implemented in the FE code ABAQUS together with the constitutive model and the dynamic cumulative criterion of spalling which is discussed below. Thus, the problem is completely coupled with temperature, including the spall criterion used.

\section{DISCUSSION OF THE SPALL CRITERIA}

Fracture is the result of variety of microscopic rate processes, but each of these processes is not accessible directly for a global analysis and modelling. Development of useful engineering models, together with the use of modern numerical methods, are of great importance and show promise for making fracture an understood and predictable event at different loading rates and temperatures.

To determine the critical conditions in spalling Cochran and Banner [7] used for example the peak of velocity on the free surface of the target when a spall occurs. In such case the velocity of the free surface does not return to zero. It was found that the ratio between the free-surface velocities of the spall to the compression pulse peaks provided a good correlation with void densities at the spall plane. A criterion based on the pull-back free-surface velocity was used in [8] to calculate the stress initiation of spall.

It is generally accepted that the rate and temperature effects are closely related to the thermally activated micromechanical processes of fracturing. The concept that thermal activation is involved in material separation during fracture processes has been pursued by Zhurkov[9]. It means in the other words that in a stressed body the creation of free surfaces occurs via thermal activation processes.

The kinetic concept of the mechanism of fracture is understood as a time process which rate is determined by stress and temperature. From this standpoint, the investigation of time and temperature factors become very important for the understanding of the mechanism of fracture phenomenon. In this spirit, systematic studies of the relationship between the life-time of solids under load and the magnitude of the tensile stress and temperature have been previously carried out, [9]. However, those studies were limited to the long-time span. In such case the relationship revealed between the life time $t_{C}$, the critical stress $\sigma_{F}$, and the absolute temperature $\mathrm{T}$ can be written in the form of kinetic equation:

$$
t_{C}=t_{C_{0}} \exp \left(-\frac{G_{0}-V^{*} \sigma_{F}}{k T}\right)
$$

where $\mathrm{k}$ is the Boltzmann constant, $\mathrm{t}_{\mathrm{co}}$ and $G_{0}$ represent material constants and $V^{*}$ is so called the activation volume. The dependence of barrier energy $\Delta H=G_{0}-V^{*} \sigma_{F}$ on stress results in sharp acceleration of the fracture process in stressed body, and in a decrease of its life time under load. Zhurkov pointed out that the identity of general law governing the life time of both polymers and metals, as well as the coincidence of the activation energy for the rate of fracture with the interatomic binding energy, permits for generalization of the kinetic concept of strength to all solids. More recently, Dremin and Molodets [10] have proposed to modify and apply the criterion (9) to spall mechanics. The modification was to some extent inconclusive since the analysis of experimental data for spalling and slow fracture revealed necessity of a complete change of parameters for the same materials at those different time scales. Klepaczko, [1,11] have proposed different approach to the Boltzmann statistics to formulate a fracture criterion for short and very short loading times. The most logic approach is to assume that the frequency of damage, or the rate of microcracks or microvoids evolution, is in the form :

$$
\dot{N}=\dot{N}_{0} \exp \left(\frac{-\Delta G\left(\sigma_{F}\right)}{k T}\right) \quad \text { with } \quad \Delta G\left(\sigma_{F}\right)=-\Delta G_{0} \ln \left(\frac{\sigma_{F}}{\sigma_{F_{0}}}\right)
$$


where $\dot{N}, \dot{N}_{0}, \sigma_{F}$ and $\sigma_{F_{0}}$ are respectively the rate of damage, the fundamental rate, the local stress and the threshold stress, $\Delta G\left(\sigma_{F}\right)$ is the stress dependent free energy of activation taken after Yokobori, $\Delta G_{0}$ is the barrier energy for non stressed body. Thus, The following cumulative fracture criterion in the integral form was proposed by Klepaczko, [1] :

$$
t_{C_{0}}=\int_{0}^{t_{C}}\left(\frac{\sigma_{F}(t)}{\sigma_{F 0}}\right)^{\alpha(T)} d t \quad ; \quad t_{C} \leq t_{C_{0}} \quad \sigma_{F} \geq \sigma_{F_{0}} \quad \text { with } \quad \alpha(T)=\frac{\Delta G_{0}}{k T}
$$

Where $\sigma_{F_{0}},{ }^{t} C_{0}$ et $\alpha(T)$ are three material constants at constant temperature $T_{0}, \mathrm{t}_{\mathrm{c}_{0}}$ is the longest critical time when $\sigma_{F}\left(t_{C_{0}}\right)=\sigma_{F_{0}}$, for $t_{C}>t_{C_{0}}, \sigma_{F}=\sigma_{F_{0}}$ and $\sigma_{F_{0}}=$ const. The exponent $\alpha(T)$ is temperature dependent and is related to the activation energy of material separation $\Delta G_{0}$, with $\mathrm{k}$ the Boltzmann constant and $\mathrm{T}$ the absolute temperature. When the process is non-isothermal, as it happens in the case of spalling, the exponent $\alpha(T)$ is time dependent via changes of temperature during loading or unloading, $\alpha(T, t)$. In this case eq.(11) must be integrated accordingly, including the temperature history $T(t)$.

\section{NUMERICAL SIMULATION AND DISCUSSION OF RESULTS}

In order to analyse the mechanics of wave propagation together with the spall phenomenon a series of numerical FE simulation has been performed for aluminum alloy 7020-T6. The constitutive equations (1)(6), the equation of heat conduction, (8) and the cumulative fracture criterion, equation (11), have been implemented in the finite element code ABAQUS (explicit version) by writing a user subroutine. The material constants used in all simulations are given in Table 1 , in addition $\beta=0.9, C_{p}=923[\mathrm{~J} / \mathrm{kg} \mathrm{K}]$. A circular target plate $d=57.0 \mathrm{~mm}$ loaded by a square pressure pulse has been analysed. The thickness of the flyer plate was assumed the same as used during the experiments, $\mathrm{L}_{1}=5.0 \mathrm{~mm}$, thickness of the target plate $\mathrm{L}_{2}=10.0 \mathrm{~mm}$. Due to radial symmetry only half of the flyer and the target has been simulated. The mesh adopted had 725 axisymmetric elements. The time increment was assumed constant, $\Delta \mathrm{t}=21.6 \mathrm{~ns}$. Most of the simulations were carried out up to the total time of $4.6 \mu \mathrm{s}$, which is sufficient for several elastic wave passages across the target thickness, and long enough for a complete spallation.

First series of numerical simulations have been performed assuming only the thermo-elastic coupling. The thermo-elastic effect due to dilatational response is usually neglected in standard calculations. It is also known that thermo-elastic increments of temperature are reversible. The increment is $\Delta T$ for the compressive wave and $-\Delta T$ for the tensile wave. In Fig. 1 are shown the thermoelastic profiles of the temperature for three impact velocities, $\mathrm{Vi}=40 \mathrm{~m} / \mathrm{s}, \mathrm{Vi}=80 \mathrm{~m} / \mathrm{s}$ and $\mathrm{Vi}=250 \mathrm{~m} / \mathrm{s}$. The reversible thermoelastic effect is clearly noted. This preliminary result confirms the correct approach to the thermal coupling.

Several simulations were performed over a range of different impact velocities. These calculations have been done to find the minimum critical stress $\sigma_{F}$ of spall-fracure as a function of the critical time of loading $t_{c}$ using criterion (11), Fig.2. It has been found that for the configuration analysed the spalling can occur above velocity $\mathrm{Vi}=80 \mathrm{~m} / \mathrm{s}$ for $\sigma_{\mathrm{F}}=1.25 \mathrm{GPa}$ and $t_{C}=1.64 \mu \mathrm{s}$. Comparison of numerical results with experiments are also shown in Fig.2, the result is correct, the spall stress $\sigma_{F}$ is increasing with the decrease of time of load. In the case of instantaneous loading, which is an ideal case without risetime, the critical spall time $t_{C}$ is slightly shorter than in the real case. Because in reality the rise time before spall fracture is not zero an introduction of the rise time is necessary in a more exact numerical scheme.

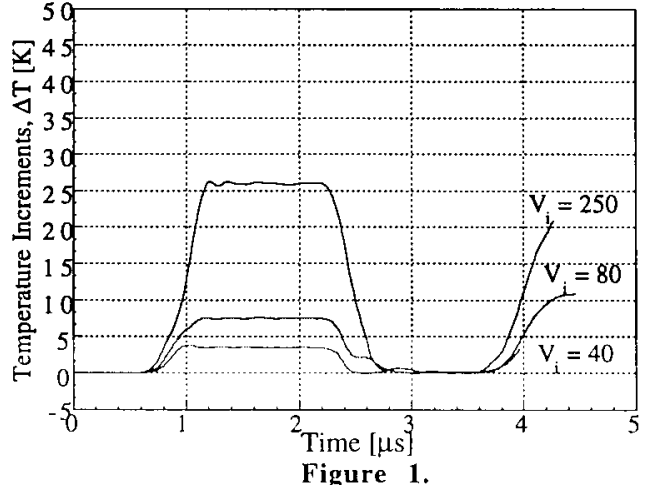

Figure 1.

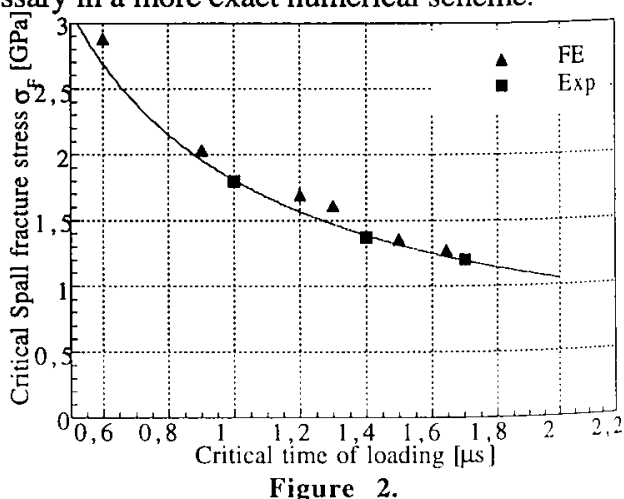

Figure 2. 
Second series of simulations was performed taking into account the elasto-viscoplastic behavior of the aluminum alloy 7020-T6, thus taking into account strain hardening, strain rate sensitivity and the temperature coupling, that is the heat generated by the volume change and the energy dissipation due to plastic work, the results are shown in Figs. 3 and 4.

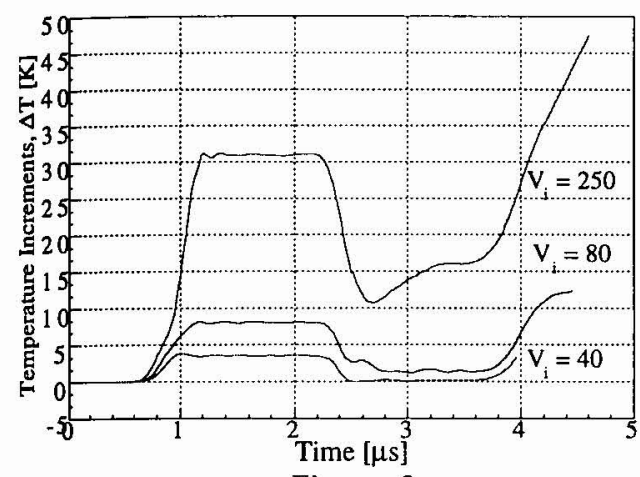

Figure 3.

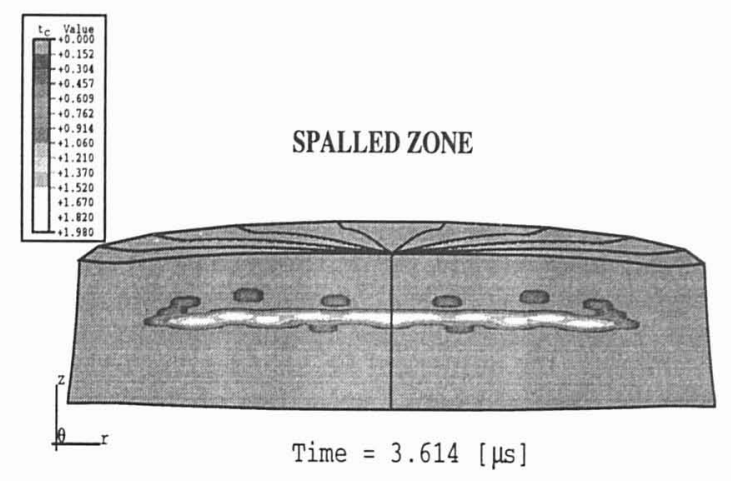

Figure 4.

In Fig.3 are shown the temperature profiles due to dilatation and dissipation of plastic work in the middle of the target plate for impact velocities $\mathrm{Vi}=40 \mathrm{~m} / \mathrm{s}, \mathrm{Vi}=80 \mathrm{~m} / \mathrm{s}$ and $\mathrm{Vi}=250 \mathrm{~m} / \mathrm{s}$. In the case of more advanced plastic deformation, the critical time is longer than for the elastic case. This is caused by a delay time in initiation of yielding and the plastic flow increases the rise time. On the other hand, the cumulation of damage until fracture is completed also requires time. In order to find numerically the critical conditions for spalling and creation of a new free surface inside the target the following technique has been applied. Upon reaching the critical conditions defined by the criterion (11) the stress in the particular element is set to zero and the element is eliminated from further calculations. This operation creates a new free surface inside the target plate giving rise to a new reflected wave, one example is shown in Fig.4 for impact velocity $\mathrm{Vi}=160 \mathrm{~m} / \mathrm{s}$ and time $\mathrm{t}=3.614 \mu \mathrm{s}$.

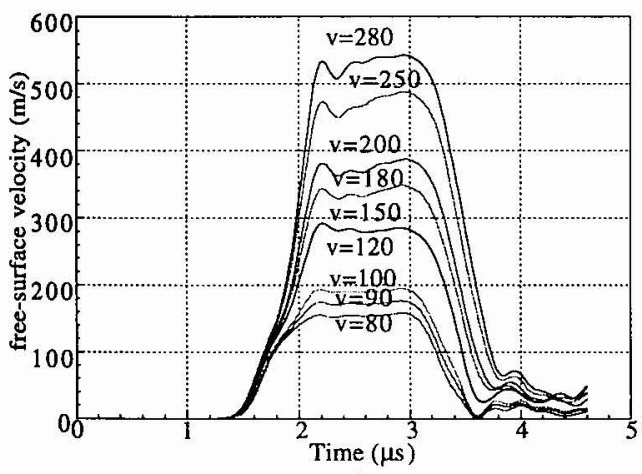

a)

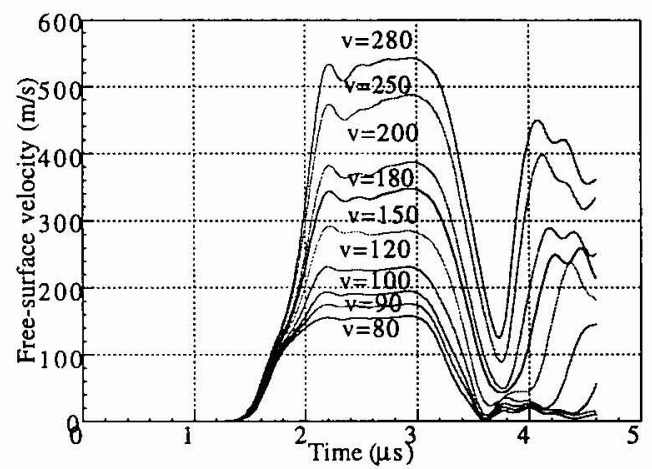

b)

Figure 5 .

Fig.5, shows the sequence of calculated free-surface velocities without spalling (no criterion assumed) and with spalling (criterion-eq.(11)), at increasing impact velocities for aluminum alloy Al 7020-T6 (flyer plate thickness $5 \mathrm{~mm}$, target thickness $10 \mathrm{~mm}$ ). When the incident velocity increases, the spall peak of the free surface velocity becomes more and more evident. The free surface velocity is well reproduced by those simulations, Results shown in Fig. 5 demonstrate occurrence of the new free surface in the interior of the target material, one example of the contour plot is shown in Fig.4.

Simulation of the free surface velocities were obtained via elimination of elements in which critical value of the cumulative fracture criterion was reached, Fig.4. After appearance of the free surface in the target interior the remainder momentum in spalled section causes additional displacement of the external part of the target. Such feature is of course observed experimentally. Since no fracture criterion in shear is introduced the external part of the target can not be separated from the rest of the target. such mechanism of the complete separation was studied in [12]. 


\section{CONCLUSIONS}

The numerical analysis reported herein clearly demonstrates the ability to predict the spall process in the aluminum alloy 7020-T6. The cumulative criterion in the form of eq(11), introduced via the special procedure in the ABAQUS FE explicit scheme enables to analyse numerically the spall over a with range of impact velocities. The range of velocities studied was between $40 \mathrm{~m} / \mathrm{s}$ and $280 \mathrm{~m} / \mathrm{s}$ with the pulse duration from $0,4 \mu \mathrm{s}$ to $1.7 \mu \mathrm{s}$. Although the calculated temperature increments are not so high the numerical scheme applied permits for studies of temperature effects on spalling, including different initial temperatures, from low to elevated. The wave mechanics analysed with the FE code assures detailed understanding of spall experiments by the plane impact technique.

The numerical simulations performed for different loading conditions reproduce exactly, for the aluminum alloy studied, the dependence of the spall stress $\sigma_{F}$ on pulse duration, Fig.2. An extent of spall damage in the target plate can be estimated numerically at different impact velocities including thermal effects. This could help in the design of new experiments.

Finally, the numerical FE scheme combined with the cumulative spall criterion, eq.(11), is able to reproduce the "pull-back" velocities of the free surface, Fig.5, caused by the creation of the internal spalling, Fig.4. In general, this numerical scheme makes possible predictions of the spall experiments, limiting at the same time a number of tests, which are complicated and expensive.

\section{References}

[1] Klepaczko J. R., Dynamic crack initiation, Some Experimental Methods and Modelling, in: Crack Dynamics in Metallic Materials, Ed. J. R. Klepaczko, Springer-Verlag, Vienna, (1990) p. 255.

[2] Meyers M. A. and Aimone C.T., Dynamic fracture (spalling) of metals, Prog. in Mater. Sci., 28, (1983) pp. 1-96.

[3] Curran D.R., Seaman L. and Shockey D.A., Dynamic failure of solids, Physics reports 147, NorthHolland, Amsterdam, 5-6, (1987) pp. 253-388.

[4] Hanim S., J.R.Klepaczko, Ecaillage sous choc plan de métaux : étude numérique et expérimentale. Actes du 2 ème Cong. de Méca. Maroc, Tome 2, (1995) p. 63.

[5] Chevrier P., Funfrock F., Automatisation et informatisation du fonctionnement d'un canon à gaz haute performance, et étude de l'endommagement dynamique d'un alliage d'aluminum soumis à une onde plane induite par un impact plaque sur plaque, Final Eng. Report, Metz University, (1994).

[6] Klepaczko J.R., A practical stress-strain-strain rate-temperature constitutive relation of the power form, J. of Mech. Work. Tech., 15, 143 (1987).

[7] Cochran S. and Banner D.: Spall studies in uranium, J. Appl. Phys., 48, (1977) p. 2729.

[8] Speight C. S. and Taylor P. F. : Dynamic fracture criteria from free surface velocity measurements, in Metallurgical Applications of Shock-wave and High-strain-rate Phenomena, Ed. by L. E. Murr, K. P. Standhammer, M. A. Meyers, (1986) p. 805.

[9] Zhurkov S. N. : Kinetic concept of the strength of solids, Int. J. Fracture, 1,.311 (1965).

[10] Dremin A. N. and Molodets A. M., On the spall strength of metals, in : Proc. of the Int. Symp. on Intense Dynamic Loading and its Effects, Science Press, Beijing, China, (1986) p. 13.

[11] Chevrier P. and Klepaczko J. R., Spalling of aluminum alloy 7020-T6, experimental and theoretical analyses, in : Proc. ECF11, Mechanisms and Mechanics of Damage and Failure, 1, EMAS, UK, (1996) p. 693.

[12] Eftis J., Nemes J. A., Constitutive modelling of spall fracture, Arch. Mech., 43, (1991) pp. 399435. 